\title{
Kemelimpahan Jenis Gulma Tanaman Wortel pada Sistem Pertanian Organik
}

\author{
Sri Utami \\ Laboratorium Ekologi dan Biosistematik Jurusan Biologi FMIPA Undip
}

\begin{abstract}
Abstrak
Gulma merupakan tumbuhan alami yang mengganggu tanaman budidaya. Keberadaan gulma yang dibiarkan tumbuh pada tanaman budidaya akan menurunkan hasil panen. Penurunan hasil panen oleh gulma disebabkan adanya kompetisi yang terjadi antara gulma dengan tanaman budidaya.. Didalam upaya meningkatkan produksi pertanian, umumnya petani menggunakan berbagai bahan agrokimia, bahan ini akan menyebabkan lingkungan menjadi rusak. Agar lingkungan tetap terpelihara baik digunakan sistem pertanian organik yaitu suatu sistem pertanian tanpa menggunakan bahan kimia yang bisa meracuni lingkungan. Salah satu jenis tanaman sayur yang banyak dibudidayakan adalah tanaman wortel. Wortel sangat diperlukan karena banyak mengandung vitamin yang sangat bermanfaat untuk kesehatan manusia. Gulma yang tumbuh di lahan wortel dapat menurunkan produksi wortel. Penelitian ini bertujuan untuk mengetahui jenis-jenis gulma wortel dan kemelimpahannya pada sistem pertanian organik. Lahan yang ditanami wortel gulmanya dibiarkan tumbuh sampai umur 3 bulan. . Dilakukan 4 macam perlakuan pemupukan organik yaitu pupuk kandang, pupuk hijau, EM-4 dan tanpa dipupuk Dilakukan sampling gulma dengan mencatat jenis-jenis gulma dan menghitung jumlah individunya. Plot yang digunakan berukuran $1 \mathrm{~m}$ x $1 \mathrm{~m}$, dan dilakukan 3 kali ulangan. Dilakukan juga pengukuran faktor lingkungan. Dari hasil penelitian diperoleh gulma yang dominan dan kemelimpahannya tinggi pada semua perlakuan adalah Drymaria villosa dan Vernonea cinerea. Jumlah individu gulma paling tinggi didapatkan pada lahan yang dipupuk dengan pupuk kandang, sedang paling rendah pada lahan tanpa dipupuk.
\end{abstract}

Key word: Gulma, Pertanian organik, Wortel, Drymaria villosa

\section{PENDAHULUAN}

Gulma merupakan tumbuhan yang tumbuh pada suatu tempat dan keberadaannya tidak diinginkan karena mengganggu tanaman budidaya atau dapat mengganggu aktifitas manusia. Dalam konteks ekologi gulma tanaman budidaya (weedcrop ecology), gulma adalah tumbuhan yang berasal dari lingkungan alami dan secara kontinu mengganggu tanaman dan aktifitas manusia dalam mengusahakan tanaman budidaya (Aldrich, 1984).

Masalah gulma sebenarnya merupakan masalah penting dalam usaha pertanian, namun tidak mendapat perhatian seperti hama atau penyakit tanaman yang lainnya. Hal tersebut disebabkan karena kerugian yang ditimbulkan oleh gulma sedikit demi sedikit tidak langsung bisa dilihat, tetapi sebenarnya sangat menurunkan hasil panen. (Moenandir et al., 1993).

Berbeda dengan organisme pengganggu lain (serangga dan jamur) yang secara visual dapat dilihat serangannya demikian drastis pada tanaman, gulma menyerang melalui kompetisi terhadap air, unsur hara, cahaya dan ruang tumbuh.
Daya kompetisi gulma tersebut dikarenakan gulma mempunyai sifat : tumbuh dengan cepat, mempunyai toleransi yang tinggi terhadap faktor lingkungan, daya berkembang biakannya besar baik secara generatif maupun vegetatif, dan biji sangat mudah disebarkan. Kehadirannya yang merugikan secara perlahan dan pasti perlu dikendalikan secara bijaksana (Aldrich, 1984).

Keberadaan gulma yang dibiarkan tumbuh pada tanaman budidaya akan menurunkan 20 $80 \%$ hasil panen. Penurunan hasil tanaman sangat bervareasi tergantung dari berbagai faktor, antara lain kemampuan tanaman berkompetisi, jenis-jenis gulma, umur tanaman dan umur gulma, tehnik budidaya dan durasi mereka berkompetisi. Gray dan Hew (1968) melaporkan bahwa Micania micrantha HBK menyebabkan kehilangan hasil tanaman kelapa sawit sebesar $20 \%$ selama lima tahun. Penurunan produksi jagung RR tanpa pengendalian gulma sebesar $31 \%$. Kerugian yang diakibatkan oleh gulma di seluruh dunia sangat besar mencapai 95 milyard US \$ per tahun dan sebagian besar terjadi di negara berkembang dan 
hal itu disebabkan pengelolaan gulma yang tidak tepat (Anonim, 2009).

Dalam rangka untuk bisa meningkatkan hasil pertanian pada umumnya para petani lebih suka menggunakan berbagai bahan agrokimia karena bahan tersebut lebih menguntungkan daripada menggunakan bahan-bahan yang akrab lingkungan. Penggunaan pupuk kimia ataupun pestisida kimia akan menimbulkan kerusakan lingkungan, diantaranya hasil pertaniannya akan mengandung residu kimia sumber daya tanah, air dan udara semakin lama akan menjadi rusak (Sutanto, 2004).Upaya untuk menjaga agar sumberdaya lingkungan tidak rusak adalah dengan melakukan sistem pertanian organik. Sistem pertanian organik adalah suatu sistem dengan cara menghindarkan bahan kimia dan pupuk yang bersifat meracuni lingkungan dengan tujuan memperoleh kondisi lingkungan yang sehat (Sutanto, 2004). Pertanian organik bertujuan untuk menghasilkan makanan yang berkwalitas dan bergizi yang mendukung kesehatan dan kesejahteraan.

.Wortel merupakan salah satu jenis sayuran yang banyak dibudidayakan, karena banyak manfaatnya untuk kesehatan. Manfaat dari wortel diantaranya sebagai sumber vitamin A, vitamin B dan vitamin C. Gulma yang dibiarkan tumbuh di lahan tanaman wortel juga akan menurunkan produksi wortel. Untuk mendapatkan produksi wortel yang tinggi, perlu dilakukan pengendalian gulma yang tumbuh di lahan tanaman wortel. Penelitian tentang kemelimpahan jenis-jenis gulma tanaman wortel pada sistem pertanian organik perlu dilakukan dengan tujuan mengetahui jenisjenis gulma dominan dengan menggunakan pupuk kandang, pupuk hijau, EM-4.

\section{BAHAN DAN METODE}

Penelitian ini dilakukan di Pusat Penelitian Pertanian Akrab Lingkungan, Wonosobo. Tanaman yang digunakan adalah wortel dengan menggunakan sistem pertanian organik. Penelitian ini memggunakan 4 macam pupuk sebagai perlakuan yaitu pupuk hijau, pupuk kandang, EM4 dan tanpa pupuk sebagai kontrol. Gulma dibiarkan tumbuh tidak disiangi sampai umur tanaman 3 bulan. Setelah tanaman wortel umur 3 bulan dilakukan sampling gulma. Ukuran plot yang digunakan $1 \mathrm{~m} \times 1 \mathrm{~m}$. Pengamatan dilakukan dengan mendata jenis-jenis gulma dan menghitung individu setiap jenisnya. Masing-masing perlakuan diulang 3 kali (tiga plot) yang diambil secara acak. Dilakukan pengukuran faktor lingkungan pada lahan tersebut.

Analisa Data:

Untuk mengetahui kemelimpahan jenis gulma dipakai indeks kemelimpahan relatif dengan rumus:

$$
\mathrm{Di}=\mathrm{ni} / \mathrm{N} \text { x } 100 \%
$$

Keterangan $: \mathrm{Di}=$ Indeks kemelimpahan jenis ke $\mathrm{i}$

ni = Jumlah individu dari jenis $\mathrm{i}$

$\mathrm{N}=$ Jumlah total individu dari seluruh jenis $\mathrm{i}$

Menurut Jorgensen (1974) dalam Krebs (1989) untuk menggambarkan komposisi jenis dibedakan :

a. Jenis dominan dengan $\mathrm{Di} \geq 5 \%$

b. Jenis sub dominan dengan $\mathrm{Di}=2-<5 \%$

c. Jenis tidak dominan dengan $\mathrm{Di}=0-<2 \%$

\section{HASIL DAN PEMBAHASAN}

Dari hasil penelitian yang telah dilakukan didapatkan 16 jenis gulma. Pada lahan tidak dipupuk (kontrol) jenis gulma yang tumbuh relatif lebih sedikit dibanding gulma pada lahan yang dipupuk. 
Tabel 1.Jumlah individu jenis/ $\mathrm{m}^{2}$ dan kemelimpahan relatif (\%) jenis-jenis gulma tanaman wortel pada pertanian organik di PPPAL Wonosobo.

\begin{tabular}{|c|c|c|c|c|c|c|c|c|c|}
\hline \multirow[t]{2}{*}{ No } & \multirow[t]{2}{*}{ Nama jenis } & \multicolumn{2}{|c|}{ TO } & \multicolumn{2}{|c|}{ FM } & \multicolumn{2}{|c|}{ GM } & \multicolumn{2}{|c|}{ EM4 } \\
\hline & & $\sum$ & Di & $\sum$ & Di & $\sum$ & Di & $\sum$ & Di \\
\hline 1 & Bidens pilosa & 8 & 3,88 & 11 & 3,78 & 9 & 3,95 & 5 & 1,81 \\
\hline 2 & Amaranthus gracillis & & & 4 & 1,37 & & & & \\
\hline 3 & Crassocephalum sp & 1 & 0,49 & 3 & 1,03 & 5 & 2,19 & 6 & 2,17 \\
\hline 4 & Erigeron sumatrensis & 4 & 1,94 & 5 & 1,72 & 2 & 0,88 & 2 & 0,72 \\
\hline 5 & Vernonea cinerea & 35 & 16,99 & 124 & 42,61 & 52 & 22,81 & 117 & 42,24 \\
\hline 6 & Drymaria villosa & 152 & 73,79 & 138 & 47,42 & 133 & 58,33 & 128 & 46,21 \\
\hline 7 & Eleusin indica & & & 2 & 0,69 & 9 & 3,95 & 6 & 2,17 \\
\hline 8 & Portulaca oleracea & 2 & 0,97 & 1 & 0,34 & 5 & 2,19 & & \\
\hline 9 & Paspalum $s p$ & & & 2 & 0,69 & & & & \\
\hline 10 & Blumea chinensis & & & & & & & 8 & 2,89 \\
\hline 11 & Ageratum coniziodes & 3 & 1,46 & & & 5 & 2,19 & 3 & 1,08 \\
\hline 12 & Comelina nudiflora & & & 1 & 0,34 & & & & \\
\hline 13 & $\begin{array}{l}\text { Spilanthes } \\
\text { iabadicensis }\end{array}$ & & & & & & & 1 & 0,36 \\
\hline 14 & Oxalis verniculata & 1 & 0,49 & & & 2 & 0,88 & & \\
\hline 15 & Cyperus rotundus & 1 & 0,49 & & & & & 1 & 0,36 \\
\hline 16 & $\begin{array}{l}\text { Ghomprena } \\
\text { celosioides }\end{array}$ & & & & & 6 & 2,63 & & \\
\hline & Jumlah jenis & 9 & & 10 & & 10 & & 10 & \\
\hline & Jumlah individu & 206 & & 291 & & 228 & & 277 & \\
\hline
\end{tabular}

Keterangan:

T0 : kontrol tanpa pupuk

FM : pupuk kandang

GM: pupuk hijau

EM4: pupuk EM-4

Hasil penelitian menunjukkan bahwa jenis gulma yang mendominasi pada lahan tanaman wortel sistem pertanian organik di P3AL Wonosobo adalah Drymaria villosa dan Vernonia cinerea. Jenis-jenis tersebut mempunyai indeks kemelimpahan $\geq 5$ dan terdapat pada semua perlakuan baik yang tanpa pupuk maupun yang dipupuk. Jenis-jenis gulma dengan indeks kemelimpahan $\geq$ merupakan jenis yang dominant (Jorgensen, 1974 dalam Krebs, 1989). Demikian juga dengan jumlah individu, kedua jenis tersebut mempunyai jumlah individu yang paling banyak bila dibandingkan dengan jenis gulma yang lain. Jumlah individu jenis yang paling banyak didapatkan pada Drymaria villosa. Dari hasil penelitian yang telah dilakukan di dataran tinggi di Tabanan Bali ditemukan jenis gulma yang mendominasi pada tanaman wortel adalah jenis
Drymaria cordata, Eleutheranthera rudealis, Axonopus compressus, Cynodon dactyllon, Ageratum conyzoides, Amaranthus bilitum dan Amaranthus gracilis (Hartati, 2003). Dari hasil penelitian tersebut diatas didapatkan gulma Drymaria merupakan gulma yang mendominasi lahan tanaman wortel.

Drymaria villosa merupakan jenis herba merayap yang tumbuh diantara tumbuh-tumbuhan lain. Bisa tumbuh di tempat cerah matahari maupun daerah dengan keteduhan sedang. Ketinggian tempat $300-1600$ dpl. Selain Drymaria vilosa jenis gulma lain yang mendominasi tanaman wortel pada penelitian ini adalah Vernonia cinerea. Gulma ini merupakan herba tegak yang tumbuh di daerah cerah matahari atau sedikit teduh dan tidak terlalu basah. Ketinggian tempat 0-1400 dpl. (Soerjani, et al. 
1987). Kedua jenis gulma tersebut mempunyai daya adaptasi dan kompetisi yang tinggi sehingga bisa mendominasi gulma lain.

Pada perlakuan To (kontrol) yaitu tanaman wortel tidak diberikan pupuk, jumlah jenis maupun jumlah individunya lebih sedikit bila dibandingkan dengan yang dipupuk (Tabel 1). Hal ini disebabkan karena pemupukan akan sangat berpengaruh terhadap kesuburan tanah, sehingga ketersediaan nutrient untuk tanaman tercukupi dan gulma bisa tumbuh lebih baik. Dari hasil analisis Tabel 2. Hasil analisis kimia tanah masing-masing perlakuan pada lahan yang ditanami wortel di P3AL Wonosobo.

\begin{tabular}{llllllll}
\hline No & $\begin{array}{l}\text { Perlaku } \\
\text { an }\end{array}$ & $\begin{array}{l}\text { Kalium } \\
(\mathrm{mg} / \mathrm{Kg})\end{array}$ & Kalium $(\%)$ & $\begin{array}{l}\text { N-organik } \\
(\mathrm{mg} / \mathrm{Kg})\end{array}$ & $\begin{array}{l}\text { N-organik } \\
(\%)\end{array}$ & $\begin{array}{l}\text { Phosfat } \\
(\mathrm{mg} / \mathrm{Kg})\end{array}$ & $\mathrm{P}(\%)$ \\
1 & T0 & 60941.6 & 6.09 & 1843.5 & 0,184 & 0.93 & 0,00009 \\
2 & FM & 48532.2 & 4.85 & 2694.6 & 0,26 & 4.55 & 0.00046 \\
3 & GM & 38025.3 & 3.8 & 2059.39 & 0.206 & 1.77 & 0.00018 \\
4 & EM & 86456.1 & 8.64 & 1864.5 & 0,186 & 1.77 & 0.00018 \\
\hline
\end{tabular}

Dari hasil penelitian yang telah dilakukan di lahan wortel dengan sistem pertanian organik menunjukkan bahwa penggunaan pupuk kandang dan pupuk hijau secara signifikan meningkatkan kemelimpahan Collembola. Sedang penggunaan EM-4 sebagai pupuk tanaman dapat menambah laju mineralisasi, meningkatkan konsentrasi $\mathrm{P}$ tanah dan meningkatkan produksi wortel (Rahadian, 2009).

Collembola merupakan mikroarthropoda tanah yang kehadirannya dapat memperbaiki struktur tanah dan meningkatkan kesuburan tanah. Penggunaan EM-4 dapat membantu mempercepat dekomposisi materi organik, karena EM-4 merupakan kultur kombinasi berbagai jenis mikroorganisme yang menguntungkan sehingga kesuburan tanah pertanian menjadi lebih baik (Higa dan Parr, 1994 dalam Rahardian, 2009).

Penggunaan pupuk kandang, pupuk hijau dan EM-4 akan menyuburkan tanah sehingga pertumbuhan gulmapun menjadi lebih baik. Jumlah individu gulma yang paling banyak didapatkan pada lahan yang dipupuk dengan pupuk kandang. Hal ini disebabkan pupuk kandang mempunyai kwalitas yang lebih baik dibanding pupuk organik lain. Pupuk kandang mempunyai nisbah $\mathrm{C} / \mathrm{N}$ yang lebih rendah dan kadar hara N, P, dan K lebih tinggi. Kecepatan dekomposisi pupuk organik dipengaruhi oleh kimia terlihat bahwa tanaman yang dipupuk dengan pupuk hijau dan pupuk kandang meningkatkan kandungan N-organik dan phospat tanah. Sedang pupuk EM meningkatkan kandungan kalium, N-organik dan phosfat (Tabel 2). Nitrogen dan fosfat merupakan dua unsur hara yang paling banyak diperlukan oleh tanaman dan merupakan pembatas pertumbuhan dan hasil atau produksi tanaman (Sutanto, 2004)

nisbah $\mathrm{C} / \mathrm{N}$. Bahan organik yang mempunyai nisbah $\mathrm{C} / \mathrm{N}$ rendah lebih cepat terdekomposisi sehingga lebih cepat tersedia sebagai unsur yang dibutuhkan tanaman.

\section{KESIMPULAN}

Dari penelitian yang telah dilakukan disimpulkan bahwa:

1. Terdapat 16 jenis gulma yang tumbuh di lahan tanaman wortel

2. Gulma dengan kemelimpahan tinggi didapatkan pada jenis Drymaria villosa dan Vernonea cinerea

3. Penggunaan pupuk organik akan menaikkan baik jumlah jenis maupun kemelimpahan gulma

\section{UCAPAN TERIMA KASIH}

Dengan selesainya penelitian ini penulis mengucapkan banyak terima kasih kepada Rully Rahadian, Ph D dan Drs, M. Hadi , MSi yang telah membantu dalam penyelesaian penelitian ini.

\section{DAFTAR PUSTAKA}

Steenis, C.G.G.J. 1978. Flora. P.T. Pradnya Paramita Jakarta.

Soerjani, M; Kostermans A.J.G.H dan Tjitrosoepomo, G. 1987. Weed of Rice in Indonesia. Balai Pustaka, Jakarta. 
Sutanto, R. 2002. Pertanian Organik. Menuju Pertanian Alternatif dan Berkelanjutan. Penerbit Kanisius Yogyakarta.

Anonim. 1990. Pengembangan Produksi Kedelai. Direktorat Jendrak Pertanian Tanaman Pangan. Direktorat Bina Produksi Padi dan Polowijo.

Aldrich, R.J. 1984. Weed-crop Ecology. Principles in Weed Management. Nort Scituate, Massachussets: Breton Publisher.

Hartati, I. 2003. Gulma Sayuran Dataran Tinggi Di Daerah Candikuning Tabanan Bali dalam Prosiding Konferensi Himpunan Gulma Indonesia Ke 9, Bogor.

Krebs, C.J. 1989. Ecological Methodology. Harper and Row Publisher, New York.
Rahadian, R. 2009. Structure of Collembola Community and Its Nutrient Mineralization As Affected by Application of Different Organik Manures and EffectiveMicroorganism. Disertasi. University of the Philippines Los Banos.

Purba, E. 2009. Keanekaragaman Herbisida Dalam Pengendalian Gulma Mengatasi Populasi Gulma Resisten dan Toleran. Pidato Pengukuhan Guru Besar Tetap Universitas Sumatera Utara, Medan

Iqbal, A. 2009. Potensi Kompos dan Pupuk Kandang Untuk Produksi Padi Organik di Tanah Inceptisol. Jurnal Ilmiah Akta Agrosia Vol. 11. Fakultas Pertanian Unsoed Purwokerto. 